Cadernos de Clio, Curitiba, n. ${ }^{\circ}$ 4, 2013

\title{
CONSTRUINDO A HELENIZAÇÃO: INTERAÇÕES CULTURAIS ENTRE GRECO-MACEDÔNIOS E AUTÓCTONES NAS OBRAS DE DROYSEN, JOUGUET E MOMIGLIANO.
}

Thiago do Amaral Biazotto ${ }^{1}$

Resumo: O objetivo deste artigo é feitura de uma discussão teórica do modelo normativo de cultura denominado helenização a partir de três obras magnas: Alexandre: o grande, de Johann Gustav Droysen (18081884), El imperialismo macedonico y la helenización del oriente, de Pierre Jouguet (1869-1949), e Alien Wisdom: The Limits of Hellenization, de Arnaldo Momigliano (1908-1987), sendo esta última fundamental no sentido de criticar e limitar a tese de uma helenização absoluta do Oriente a partir das conquistas de Alexandre Magno. Longe de se constituir num conceito estanque, portanto, a helenização possui traços e enunciações que estão em consonância com as épocas em que é formulada, fazendo da reflexão dos porquês de estas diferenças um salutar exercício de pensamento histórico.

Palavras-chave: Helenização; Helenismo; Modelos normativos de cultura; J. G. Droysen; P. Jouguet; A. Momigliano.

Mundo Antigo e modelos normativos modernos: Helenização e Aculturação

Quando repousamos nossos olhos sobre os saltérios Alexandre: o grande, de Johann Gustav Droysen (1808-1884), lançado originalmente em 1833, El imperialismo macedonico y la helenización del oriente, de

${ }^{1}$ Graduando em História pela Universidade Estadual de Campinas. Bolsista de Iniciação Científica do CNPq, com pesquisa sob a orientação do Prof. Dr. Pedro Paulo Abreu Funari. Contato através do e-mail: thiago_a_b@yahoo.com.br. 
Pierre Jouguet (1869-1949), cujo ano de publicação original é 1926, e Alien Wisdom: The Limits of Hellenization, de Arnaldo Momigliano (1908-1987), que veio a lume em 1975, com o objetivo de avaliarmos como se dão as relações culturais entre os grego-macedônios e autóctones, nessas obras, durante o período Helenístico - compreendido desde as conquistas de Alexandre Magno (356 - 323 a.C.) até a morte da rainha egípcia Cleópatra (69-30 a.C.), data que encerra a Dinastia Ptolomaica (HÜBSCHER, 2010: 48) - é patente discutirmos o conceito de helenização, presente nos três alfarrábios supracitados. Este conceito, embora se refira a sociedades e culturas pretéritas, é de origem moderna e, portanto, possui data e local de nascimento definidos: durante o século XIX, no contexto de unificação do Estado alemão - sob o espectro da Prússia - e reporta-nos aos escritos do historiador Johann Gustav Droysen (FUNARI \& GRILLO, 2012: 2).

Como ocorre com quase todos os conceitos das ditas ciências humanas, encontrar uma definição peremptória do vocábulo helenização é tarefa hercúlea. Como parti pris, neste artigo adota-se a seguinte formulação, a cargo de Rachel Mairs e extraída do The Encyclopedia of Ancient History, organizada pela Universidade de Oxford:

Helenização refere-se à propagação da cultura grega e sua adoção por povos não-gregos. O termo é mais comumente usado referindose ao período após Alexandre, o Grande. (...) Noções modernas de "Helenização" podem envolver todos os tipos de comportamento cultural, do uso da língua à adoção de vestimentas gregas e de sua cultura intelectual. Um lugar ou grupo de pessoas podem ser descri- 
tos como "sendo helenizados" como receptores passivos de influência cultural (MAIRS, 2011: 1-2)²

Portanto, a helenização tem como tese magna a difusão da cultura greco-macedônia sobre o Mundo Antigo e as populações autóctones que, por seu turno, aceitaram de bom grado os ditames culturais de seus conquistadores. Este processo de helenização seria exprimido e atestado pelo fato de os locais aprenderam o grego koine - uma vertente do grego clássico -, adotarem a cultura material trazida desde a Hélade e, em larga medida, emularem os costumes e atitudes - tidos por superiores por certa histografia - dos seguidores de Alexandre. Aos autóctones, destarte, era facultada a habilidade de tornarem-se gregos, mediante esta emulação.

Por se tratar de um conceito moderno, a helenização foi erigida tendo como ponto de partida outro princípio, o de aculturação. Não obstante ter sido definida de modo mais sistemático por antropólogos americanos na década de 1930 - como R. Redfield, R. Linton e M. Herskovits, compiladores do Memorandum for the study of acculturation, que será esmiuçado mais a diante - a aculturação tem seus matizes enraizados no século XIX. Nela, tem-se como premissa teórica que as sociedades marcham em

${ }^{2}$ Todas as traduções presentes neste artigo foram feitas pelo seu autor. Os trechos no original serão colocados nas notas de rodapé. "Hellenization refers to the spread of Greek culture and its adoption by non-Greek peoples. The term is most commonly used with reference to the period after Alexander the Great (...) Modern notions of "Hellenization" can encompass all kinds of cultural behavior, from language use, to the adoption of Greek forms of dress, to intellectual culture. A place or a group of people maybe described as having "been hellenized," as passive recipients of cultural influence (MAIRS, 2011 : 1 - 2 )" 
direção a um todo estável e homogêneo, num processo segundo o qual as classes tidas como subalternas emulam e assimilam, de maneira axiomática, os preceitos culturais de seus superiores, de maneira a se admitir que os sujeitos sociais que não se enquadram neste processo sofrem de algum tipo de desvio. (FUNARI \& GRILLO, 2012: 1-2) Estabelece-se, assim, toda uma série de oposições binárias entre superior/inferior, colonizador/colonizado e civilizado/ bárbaro, que - em longo prazo e por meio dos processos de aculturação - tendem a ser superadas, uma vez que as práticas culturais tidas como mais excelsas exultariam de forma irrefragável, eliminando tais binarismos. Deste modo, chegar-se-ia à homogeneidade social, exprimida pelos três pilares do Estado Nacional moderno: uma terra, um povo, um idioma, preceitos oriundos do século XIX. (FUNARI \& GARRAFFONI, 2012: 3).

Ciente de todo o debate epistemológico e conceitual em torno da aculturação, a Social Science Research Council (EUA), nomeou um comitê para discutir este conceito. De forma a sistematizar e divulgar as ilações obtidas naqueles encontros e, ademais, resumir como fora norteada a ideia de aculturação presente nas pesquisas até aquela data, foi publicado em 1936 o Memorandum for the study of acculturation, a cargo de R. Redfield, R. Linton e M. Herskovits. De maneira esquemática, a aculturação é definida da seguinte maneira nesse texto:

Aculturação compreende aqueles fenômenos que resultam quando grupos de indivíduos com diferentes culturas entram em contato contínuo de primeira mão, com alterações posteriores nos padrões 
culturais originais de um ou de ambos os grupos (REDFIELD, LINTON \& HERSKOVITS: 1936: 149). ${ }^{3}$

Desta definição, chega-se ao seguinte entendimento quanto às resultantes oriundas do contato de grupos de diferentes práticas culturais: “aceitação”, segundo a qual o processo de aculturação faz com que uma maior porção de uma cultura se sobreponha à outra, ocasionando a perda de grande parte da herança cultural da segunda. Isto se dá com consentimento dos membros do grupo tido como aculturado, e, como resultado, chega-se a uma assimilação não apenas de os padrões de comportamento, mas de valores internos da cultura. Também se pode chegar à “adaptação”, na qual os traços originais e estrangeiros são combinados de modo harmônico, promovendo um mosaico histórico, com uma reformulação dos padrões das duas culturas em um todo concordante, salutar para os indivíduos envolvidos, com a remissão de atitudes mais ou menos conflitantes. Por fim, tem-se a “reação", em que, por conta da opressão do estrangeiro, ou por causa dos resultados imprevistos na aceitação de seus traços, surgem movimentos contra-aculturativas, que desejam manter as raízes culturais autóctones, ora como compensação para uma inferioridade imposta ou assumida, ora como um movimento de exaltação das práticas culturais nativas, por meio de um retorno às antigas condições préaculturativas. (REDFIELD, LINTON \& HERSKOVITS: 1936: 152)

\footnotetext{
${ }^{3}$ No original: “Acculturation comprehends those phenomena which result when groups of individuals having different cultures comes into continuous first-hand contact, with subsequent changes in the original cultural patterns of either or both groups” (REDFIELD, LINTON \& HERSKOVITS: 1936: 149)
} 
Demonstradas, mesmo que em linhas gerais, as teses centrais da helenização e da aculturação, pode-se afirmar que seus pontos de contato dão-se da seguinte forma: se na aculturação apregoa-se, entre outros que o inferior busca emular seu superior, a helenização toma de assalto este tropo e aplica-o ao Mundo Antigo, brandindo os greco-macedônios como arautos da cultura, da ciência, da sobriedade e do pensamento crítico e, por conseguinte, superiores aos seus combatentes vindos dos rincões orientais. Ao conquistarem as inermes terras asiáticas, fariam com que os autóctones passassem a emular de modo acrítico suas ações, assimilando de forma passiva as práticas culturais carregadas pelos exércitos de Alexandre. Desta maneira, após suas conquistas, não haveria mais egípcios, persas, indianos ou judeus: haveria apenas greco-macedônios. E a helenização seria a responsável por esta transformação.

Tais linhas teóricas, outrossim, têm sido duramente criticadas desde a segunda metade do século XX, fruto de reivindicações de grupos socialistas, anarquistas, feministas, comunistas e libertários diversos que, cada qual a seu modo, desafiaram as pérfidas dicotomias que se consubstanciam em cisões da estirpe de civilizado/bárbaro, superior/inferior e aculturador/aculturado. A respeitável capilaridade de tais grupos acabou por influenciar a teoria social, propondo modelos de interpretação cultural mais matizados e fluídos, atentando às diversidades encontradas no interior de quaisquer agrupamentos humanos, sejam relativos à etnia, à sexualidade, à condição econômica ou às práticas culturais, entre muitos outros (FUNARI \& GARRAFFONI, 2012: 2-4). Estas críticas aos modelos normativos de cultura, naturalmente, atingiram a aculturação e a helenização. 
No que concerne à aculturação, afirma-se que este conceito está impregnado de noções que visam à alegação de uma notável superioridade europeia, da passagem da cultura autóctone à estrangeira como marco de progresso inefável, num jogo em que a gramática cultural é em absoluto comandada pelo status de civilizado, branco, sóbrio, heterossexual e austero do conquistador, seja ele um gentleman britânico ou - num processo análogo que usa dos acontecimentos do passado como roteiro para as ações do presente - um destemido combatente do exército de Alexandre. A aculturação, em suma, propugna "um programa no decorrer do qual o indivíduo ou a sociedade se aproximasse do modelo ocidental” e que "realiza um corte artificial (e carregado de duvidosa ideologia) que separa as sociedades ditas 'primitivas' e as sociedades propriamente 'históricas'” (WATCHEL, 1995: 113 e 122).

No que diz respeito à helenização, declara-se que este modelo normativo de cultura foi forjado com o objetivo definido de lastrear os feitos das potências europeias imperialistas dos séculos XIX e XX (FUNARI, 2004: 7). Advoga-se também ser um conceito por demais excludente, posto que ignora as influências dos povos autóctones para a edificação cultural do período Helenístico (MAIRS, 2011: 5), limitando todos os complexos processos de interação cultural na Antiguidade a uma estreita e rígida passagem de uma civilização inferior à outra superior (FUNARI \& GRILLO, 2012: 7), em consonância com o moderno imperialismo europeu que enxergava as conquistas de Alexandre como marcos de avanço e progresso, da mesma forma que apreciava seus atos de colonização e intervenção política e econômica nas terras africanas e asiáticas. Como resumem Funari e Garraffoni: "Todos os princípios normativos por detrás 
de conceitos como helenização e romanização foram aplicadas ao Mundo Antigo em projetos imperiais modernos" (FUNARI \& GARRAFFONI, 2012: 4). ${ }^{4}$.

Foi dito no início deste artigo, que não existe consenso quanto a uma definição cabal do conceito de helenização. Tal se dá, entre outros, em virtude das múltiplas formas como este modelo normativo de cultura tem sido trabalhado ao longo do tempo. Nas próximas sessões, seguindo esta linha mestra, veremos três momentos distintos nos quais a helenização foi formulada: nos escritos de Droysen, no contexto de unificação do Estado Alemão durante o século XIX, nas páginas de Jouguet, na primeira metade do século XX e, portanto, no coração da ação imperialista francesa e, por último, nos trabalhos de Momigliano, responsável por propugnar uma visão mais matizada do quadro cultural do Mundo Helenístico, criticando e limitando a tese de uma helenização absoluta do Oriente a partir das conquistas de Alexandre Magno, em relação harmoniosa com a teoria social do seu tempo, que assistia à criação de termos conceituais como creolização, hibridismo e mestiçagem. Tentar-se-á, deste modo, fazer uma breve resenha histórica dos usos do vocábulo helenização, desde seu enunciado como um triunfo cultural grego até os tempos hodiernos nos quais, como bem notou Peter Burke: “Os historiadores da Antiguidade (...) estão se interessando cada vez mais pelo processo de "helenização”, que estão começando a ver menos como uma simples imposição da cultura

\footnotetext{
${ }^{4}$ No original: "All the normative tenets behind such concepts as Hellenisation and Romanisation were applied to the ancient world in modern imperial projects" (FUNARI \& GARRAFFONI, 2012: 4).
} 
grega (...) e mais em termos de interação entre centro e periferia” (BURKE, 2003: 20).

\section{A Helenização em Droysen, Jouguet e Momigliano: uma história em três tempos}

Johann Gustav Droysen nasceu em Treptow, na Pomerânia, a 6 de julho de 1808. Desde cedo, demonstrou grande interesse pela Antiguidade Clássica, aprendendo rapidamente grego e latim. Em 1826, ingressa na Universidade de Berlin, tomando aulas de filologia clássica de August Boeckh, e, pouco depois, se inicia na severa disciplina da epigrafia, se ocupando de decifrar inscrições em moedas e papiros. Grande influência nos escritos do prussiano foi a carreira fulgurante de Napoleão, que fez toda a Europa repensar o poder do indivíduo e de seus atos, bem como o papel do conquistador na Antiguidade e na modernidade, de forma a considerar que o francês seguia a nobre linhagem que tinha em César e no próprio Alexandre seus mais ilustres representantes. (MÉCHIN, 2010: 1718). Em 1829, o erudito fica órfão, sendo acolhido por uma família de ricos banqueiros de Berlin, os Mendelssohn. No seio de tal abastada linhagem, travou contado com alguns dos maiores luminares da ciência germânica do século XIX, como Alexander Von Humboldt e Georg Hegel, de quem passou a ser admirador confesso. Em 1831, Droysen termina seu doutorado de título On the Kingdom of the Lagids under Ptolemaus IV Philomethor (SOUTHARD, 1994: 11) e começa, ademais, suas atividades políticas, propondo a unificação da Alemanha sob as austeras rédeas prussianas, fato que - de acordo com algumas correntes - é precípuo pra en- 
tendimento de suas elocuções acerca do período helenístico (CUSTÓDIO, 2006: 236, FUNARI \& GRILLO, 2012: 2.). Em 1833, por fim, Droysen lança seu magnum opus: Geschichte Alexanders des Grossen. Sob sua pena e escrita com as indeléveis tintas de sua colossal erudição, essa obra inaugura o termo erudito Helenismo na era moderna, para se referir à cultura greco-macedônia que triunfou, assim como as armas das falanges alexandrinas, por sobre as indomáveis hordas asiáticas. Já na página 37 de sua biografia sobre o conquistador, Droysen disserta da seguinte maneira acerca dos porquês do êxito dos greco-macedônios sobre seus pugnadores persas, numa escaramuça que, ademais, findou o conflito perpétuo a que os povos do Oriente e do Ocidente estavam condenados:

Alexandre, os encerrou (os conflitos entre Oriente e Ocidente) ao aniquilar o império dos persas, ao conquistar todo o território situado entre o deserto africano e a Índia, ao afirmar a supremacia da civilização grega sobre a cultura declinante dos povos asiáticos. Enfim, ao gerar o helenismo. Seu nome assinala o fim de uma época e o começo de uma nova (DROYSEN, 2010: 37).

O Helenismo - esta semente cultural que floresceu sobre os campos de batalha calcinados pela marcha dos soldados de Alexandre - é razão magna da vitória e, sobretudo, da consolidação das conquistas dos grecomacedônios. Os valores culturais trazidos desde a Hélade até a Ásia foram, pari passu, se fundindo com as práticas locais, até afirmarem seu caráter racional e democrático, constituindo-se no grande monumento aos triunfos do herói da Macedônia: a civilização helênica:

A alma asiática é, de maneira geral, mais altiva, mais uniforme e mais limitada que a alma ocidental. Era impossível fazer tabula 
rasa dos seus preconceitos e costumes, bem como da individualidade profunda dos povos orientais. O trabalho de assimilação só podia se efetuar lentamente, por etapas sucessivas (...). O que triunfou sobre o Oriente, em última instância, não foram os gregos, mas a civilização helênica. Por esse fato, ela se investiu de uma importância primordial. Os elementos dessa civilização (...) eram o racionalismo e a autonomia democrática (DROYSEN, 2010: 330. Grifos no original)

As conquistas militares dos exércitos greco-macedônios promoveram auspícios para os conquistados: em virtude de sua proeminência cultural, o advento de Alexandre não lançou aos sobrepujados - e aos próprios helenos - a mão de ferro típica dos conquistadores asiáticos, mas representou a chegada de uma nova e esplendorosa cultura (DROYSEN, 2010: 473). O êxito do helenismo no Oriente, portanto, fez a razão exultar, de forma tal que Bosworth (2006:5) alega ser este um regime, no entender de Droysen, pautado por ilustração cultural e princípios políticos, responsáveis primeiro por conquistar e depois civilizar o mundo, num processo que deveria ser repetido na era moderna. As ações monumentais de Alexandre Magno e seus seguidores deveriam servir de admoestação aos prussianos de seu tempo, a quem era reservado o devir de unificar o Estado Alemão. A Macedônia é travestida como a Prússia da Antiguidade. Como asseveram Funari e Grillo:

O período helenístico foi de caráter formativo, no qual se verificou o estabelecimento de um Estado unitário, prefigurando, de certa maneira, o processo de reunificação da Alemanha de seus dias, situação que facilitava a aceitação da figura de Alexandre como inaugurador de uma nova era baseada em princípios culturais e políticos que conduziam a um mundo civilizado. (FUNARI \& GRILLO, 2012: 2). 
Cadernos de Clio, Curitiba, n. ${ }^{\circ}$ 4, 2013

Neste cenário de Império Helenístico - coeso graças à obra de Alexandre - surge o conceito de “helenização”, ou seja, a adoção acrítica dos apanágios culturais helênicos pelos vencidos, que se enraizou de forma profunda na historiografia subsequente (ALCOCK, 1994: 171). A primeira menção do vocábulo helenização dá-se na seguinte passagem

Nada podia contribuir tanto para a helenização dos povos quanto habituar a juventude persa aos regulamentos militares macedônicos, acolhê-los em pé de igualdade no seio do exército imperial e insuflar-lhe um espírito militar que desempenhava nele o papel do espírito nacional, de modo que o império unificado engendrasse um novo patriotismo (DROYSEN, 2010: 448-9).

A mensagem de Droysen é clara: a helenização dá-se primeiro nas fileiras do exército. As campanhas militares dos greco-macedônios no Oriente promoveram a incorporação de grupos de soldados vencidos em suas fileiras, como forma de fomentar seu regimento para os futuros embates. Ao entrarem em contato com a sobriedade moral, a rigorosa disciplina e a superioridade bélica inerentes aos campeões de Alexandre, os asiáticos passariam a notar - e a incorporar - os hábitos que regiam a vida nos campos de batalha dos conquistadores gregos. Ao tomarem ciência do quanto tais costumes eram salutares, passariam de bom grado a adotá-los. A helenização nasce do exército, grupo mais egrégio dentro do quadro social helenístico, responsável por disseminar os eminentes valores culturais greco-macedônios sobre as longínquas paragens asiáticas.

As analogias entre a helenização como meio de disseminação cultural e o desejo de repetir este processo na era moderna - com o alvorecer 
do Estado Alemão colorido pelas cores vivas de grandeza cultural e da pujança dos agrupamentos militares da Prússia - são nítidos. Se a helenização promoveu a coesão cultural entre os auspiciosos valores grecomacedônios e a brutalidade das hordas asiáticas, o triunfo dos ditames culturais prussianos deveriam capitanear esta nova potência germânica rumo ao destino de legisladores da era Moderna. Como assevera Southard: “A análise de Droysen do presente alemão e seu esboço do futuro alemão influenciou categoricamente em sua pesquisa concorrente sobre História da Grécia Antiga.” (SOUTHARD, 1994: 19) ${ }^{5}$.

O conceito de Helenização que nasce com Droysen se tornou deveras popular e toda uma série de alfarrábios foi escrita tendo nas letras do erudito prussiano sua influência. O tomo El imperialismo macedonico y la helenización del oriente, de Pierre Jouguet, é exemplo lapidar. Jouguet nasceu em 1869, foi estudante na Escola Francesa de Atenas (1894-1897), obteve o título de Doutor em Letras (1911), pela Universidade de Lile, tornando-se professor desta mesma instituição, até 1920, e também responsável pela fundação de seu instituto de papirologia. No mesmo ano, ingressa nas incensadas cátedras da Sorbonne, tornando-se seu professor até 1928. Também digno de nota foi sua ocupação como Presidente da Sociedade Real Egípcia de Papirologia e sua amizade com Fuad I (18681936), sultão e posteriormente Rei do Egito, sendo bem sucedido em sua carreira - tal como descrito em seu obituário - “respeitando a ordem dos

5 "Droysen's analysis of the German present and his sketching of the German future drew heavily on his concurrent research into ancient Greek history.” (SOUTHARD, 1994: 19) 
Cadernos de Clio, Curitiba, n. ${ }^{\circ}$ 4, 2013

valores humanos e científicos na pesquisa pela verdade” (PEREMANS, 1950: 1577$)^{6}$.

Publicado em 1926, El imperialismo macedonico y la helenización del oriente carrega em suas mais de cinco centenas de páginas um forte verniz imperialista europeu moderno impregnado na análise das conquistas de Alexandre Magno. Jouguet defende que os greco-macedônios lograram êxito em sua empreitada muito mais em função de sua capacidade intelectual e cultural do que por seu arsenal bélico: “(...) A dinastia triunfou. Mas não deve a vitória apenas a suas armas e suas concessões, pois não haveria podido vencer se o helenismo não tivesse penetrado em todo o país (JOUGEUT, 1927: 425) ${ }^{7}$. Este helenismo - entendido como os valores culturais da Grécia clássica, representados principalmente pela vida em núcleos urbanos - promoveu aquilo que o historiador francês chama de "helenização do Oriente": a adoção acrítica dos costumes gregos pelos autóctones. Esta helenização promoveu à luz interpretativa do colonialismo europeu dos séculos XIX e XX avanços incontestáveis para as planícies asiáticas, atestados pela fundação de cidades, florescimento econômico, aumento do poderio militar, entre outros. Para Jouguet, a helenização é acontecimento dado e indiscutível, pois não haveria sentido numa eventual recusa por parte dos nativos dos ditames culturais estrangeiros, tidos por superiores. Sendo assim, o imperialismo macedônio se distingue de seus pares orientais (JOUGUET, 1927: 6) por fundamentar-se na dissemi-

6 “(...) respectant l'órde des valeurs humaines et scientifiques à La recherche de La vérite”. (PEREMANS, 1950: 1577)

7 “(...) La dinastia ha triunfado. Pero no debe la Victoria solamente a sus armas y a sus concesiones, pues acaso no habría podido vencer si el helenismo no hubiera penetrado en todo el país” (JOUGUET, 1927: 425)”. 
nação de valores intelectuais em detrimento à opressão militar. Este imperialismo levou a cabo muito mais que escravidão e selvageria. Produziu inversamente ao que se poderia supor - a civilização. O imperialismo macedônio e a helenização do Oriente, assim, se consubstanciam no nascimento de uma nova civilização, fruto de uma suposta superioridade técnica dos gregos. Quaisquer associações, portanto, entre os traços culturais helênicos e locais seriam deletérias para os primeiros:

Se o helenismo tivesse concentrado mais suas forças, acaso poderia assegurar-se de uma existência ao menos tão duradoura e mais vigorosa; organizado mais estritamente, acaso teria se difundido menos pelo mundo e teria se defendido melhor do que teve de influência do Oriente, que foi deletério para seu verdadeiro espírito. (JOUGUET, 1927: 151). ${ }^{8}$

As teses de Jouguet, de uma inconcussa helenização do Oriente como consequência da sóbria e excelsa cultura grega, têm sido criticadas de forma ríspida, por conter em seu edifico teórico alicerces moldados em consonância com o moderno discurso imperialista europeu, que, por mais que dilapidasse e espoliasse os continentes asiático e africano, alegava ilustrar essas paragens, levando até elas o avanço e o progresso. Como pontua Funari: “As analogias entre o imperialismo francês e o macedônico seguramente não estavam longe das preocupações de Jouguet” (FUNARI, 2003: 40).

8 "Si el helenismo hubiera concentrado más sus fuerzas, acaso habría podido asegurarse una existencia al menos tan duradera y más vigorosa; organizado más estrechamente, acaso se hubiera difundido menos por el Mundo y se hubiera defendido mejor de lo que en la influencia del Oriente fué deletéreo para su verdadero espíritu.” (JOUGUET, 1927: 151). 
A publicação de Alien Wisdom: The Limits of Hellenization, por Arnaldo Momigliano, promoveu extraordinária mudança nos estudos acerca do Mundo Helenístico. Lançados no ano de 1975 - reunindo conferências proferidas em maio de 1973, em Cambrigde, e em fevereiro e março de 1974, no Bryan Mawr College (HÜSBCHER, 2010: 8) - os escritos de Momigliano foram de precípua importância para a renovação dos estudos helenísticos, ao desdizer a tese de uma helenização absoluta dos povos com os quais os greco-macedônios tiveram contato. Nascido em Caraglio, na região do Piemonte, no norte da Itália, Momigliano inicia seus estudos na Faculdade de Letras da Universidade de Torino, sob a tutela de outro baluarte da erudição italiana: Gaetano De Sanctis. Em 1936, foi apontado para a cátedra da História Romana para esta Universidade, cargo do qual foi afastado em 1938, em consequência das leis raciais do governo de Mussolini, que afetaram o erudito italiano de ascendência judia.

Formulação básica do erudito piemontês diz respeito à “descoberta” de novos povos pelos gregos desde a expansão de Alexandre, o que teria fomentado uma intensa curiosidade sobre tais agrupamentos, concorrendo para que os conquistadores passassem a avaliar seus traços culturais cotejando-os com o dos nativos, assimilando, rejeitando e adaptando as singularidades que encontravam em seu caminho. Nascia, desta forma, o conceito de Alien Wisdom: a "sabedoria bárbara” que os greco-macedônios descobriam em suas conquistas, passando a adotar alguns saberes e práticas dos novos povos a seu bel prazer. (MOMIGLIANO, 1991: 10)

O quadro cultural da civilização helenística, para Momigliano, era bastante heterogêneo, de forma que seus alicerces não são políticos ou 
econômicos, mas, sim, culturais (HÜBSCHER, 2010: 48). A helenização, portanto, não se traduz numa propagação da cultura grega pelo Mundo Antigo que fez com que os autóctones a adotassem e se “tornassem” gregos. A helenização tem limites - geográficos e culturais - e as respostas dos locais aos avanços greco-macedônios foram diversas e heterogêneas. A adoção, em maior ou menor escala, de costumes gregos não representava uma assimilação axiomática de uma cultura superior, mas, sim, estratégias das populações locais como forma de reação ao advento dos exércitos de Alexandre, adotando da cultura estrangeira apenas aquilo que melhor os aprouvesse e, ademais, adaptando-a a seus próprios esquemas, vendo os apanágios culturais helenísticos de acordo com sua própria cosmovisão. Ao contrário de uma helenização comandada pelos portadores do helenismo, Momigliano propõe relações culturais multifacetadas que são dirigidas por todos os atores envolvidos no proscênio cultural da civilização helenística. Como defende o próprio:

“A civilização helenística permaneceu grega na língua, nos costumes e, sobretudo na consciência de si mesmos. (...) Isso significou que judeus, romanos, egípcios fenícios, babilônios e até indianos (...) se inseriram na literatura grega com suas próprias colaborações (...). No panteão grego foram admitidos mais deuses estrangeiros do que em qualquer época desde a pré-história (...). Era um sincretismo assimétrico que foi particularmente bem sucedido na Itália (Etrúria e Roma), deixou sua marca em Cartago, na Síria e no Egito, foi mal sucedido na Judéia, bastante insignificante na Mesopotâmia e afetou pelo menos a iconografia senão a essência da religião indiana por meio da arte gândora. A noção de um saber bárbaro conquistou estabilidade e aceitação entre aqueles que consideravam gregos” (MOMIGLIANO, 1991: 13-14). 
Sendo Momigliano um douto que, como afirma Finley, estabelecia em suas formulações relações “(...) entre as ideias e a realidade social, entre o tópico que estava sendo examinado e sua historiografia, entre o Mundo Antigo e o moderno, inclusive o nosso (...)” (FINLEY, 1989: 767), parece ser plausível afirmar que o erudito italiano tenha sofrido ascendência dos movimentos sociais modernos, mencionados no início deste artigo, que propunham modelos de interpretação cultural mais matizados e plurais. Também é de bom tom lembrar as perseguições políticas e raciais sofridas pelo catedrático italiano durante os anos de Mussolini, que o levaram a buscar exílio na Inglaterra (HÜBSCHER, 2010: 6). Todo esse quadro social e pessoal pode ter contribuído para que Momigliano refutasse ou limitasse - a hipótese da helenização do Oriente como consequência primeira das conquistas militares de Alexandre. Embora não atacasse abertamente os primeiros postulantes do conceito de helenização, sua tese que os contatos culturais entre greco-macedônios e autóctones resultaram em muito mais que o triunfo do gênio grego tornou-se sobremodo influente nas pesquisas hodiernas sobre o Mundo Helenístico, cada vez mais atentas às inflexões culturais dos nativos na construção de seu quadro social e nos subtratos políticos na edificação de seus saberes.

\section{Considerações finais}

Este artigo objetivou fazer, mesmo que de modo introdutório, uma discussão teórica sobre o modelo normativo de cultura denominado helenização, usando das obras lapidares de Droysen, Jouguet e Momigliano como estudo de caso. Viu-se como o conceito de helenização possui apa- 
nágios que estão na dependência da época em que é formulado: seja como a enunciação do nascimento de uma era marcada pela magnitude cultural dos seguidores de Alexandre - em nítidas analogias com a formação do Estado Alemão -, seja como o triunfo cultural grego a civilizar as indistintas hordas asiáticas, em consonância com os intentos imperialistas franceses dos séculos XIX e XX, seja como mais uma das múltiplas vias de interação cultural na Antiguidade, da mesma forma que se apregoa o multiculturalismo dos tempos contemporâneos, este conceito está longe de possuir ideias plasmadas e definições cabais. Investigar quais são as raízes ideológicas e os substratos políticos que sustentam conceitos modernos aplicados à Antiguidade parece ser uma das mais fulcrais ocupações do historiador que se debruça sobre o Mundo Antigo, conforme defende Silva:

Talvez caiba à História da Antiguidade, de modo geral, hoje, uma percepção maior acerca de suas apropriações, acerca do papel que desempenhou e desempenha em relação às construções identitárias, às reivindicações políticas, enfim, aos mais distintos jogos discursivos (SILVA, 2007: 32).

Já se sabe que a História em geral e a História Antiga em particular estão longe de se constituir em esforços neutros, em ciências aprisionadas numa “torre de marfim”, mas, sim, em áreas marcadas por atitudes francamente políticas, conforme proposto por Bernal (2005: 9). Assim sendo, parece ser de bom tom voltarmos nossa atenção às formas como diversos discursos sobre a Antiguidade foram articulados de maneira a sustentar posturas e modelos normativos do presente. Cabe a nós, estudiosos do Mundo Antigo, que não nos esqueçamos que, da mesma forma que des- 
construímos a produção historiográfica que nos antecedeu, tal procedimento pode e deve ser aplicada à nossa própria, sob a pena de reproduzimos um fantasioso “campo neutro e apolítico dentro do qual os estudos clássicos pudessem funcionar” (HINGLEY, 2010: 92-3). Espere-se que este objetivo tenha sido atingido com este artigo.

\section{Referências bibliográficas}

ALCOCK, S. "Breaking up the Hellenistic world: survey and society" in MORRIS, I. Classical Greece: ancient histories and modern archaeologies. New York: Cambridge University Press, pp. 171- 190, 1994

BERNAL, M. “A imagem da Grécia Antiga como uma ferramenta para o colonialismo e para a hegemonia européia” In: Textos Didáticos - Repensando o Mundo Antigo. IFCH/UNICAMP. n 49 - abril, pp. 13-31, 2005

BOSWORTH, A. "Alexander the Great and the creating of the Hellenistic age”. In: BUGH, G. (ed.) The Cambridge companion to the Hellenistic world. Cambridge University Press, pp 9-27, 2006.

BURKE, P. Hibridismo cultural. São Leopoldo: UNISINOS, 2003.

CUSTÓDIO, P. Alexandre Magno: aspectos de um mito de longa duração. São Paulo: Annablume, 2006.

DROYSEN, J. Alexandre: o grande. Rio de Janeiro: Contraponto, 2010.

FINLEY, M. “A tradição histórica: os Contributi de Arnaldo Momigliano” in Uso e abuso da história. São Paulo: Martins Fontes, pp. 75-87, 1989.

FUNARI, P. P. A. A Arqueologia Clássica e a construção da Antigüidade. História e-História, pp. 1-7, 07/09/2004, 2004

Antiguidade Clássica: a História e a Cultura a partir dos documentos. Campinas: Editora da Unicamp, 2003. , GARRAFFONI, R. Discussing acculturation as an interpretive model: Romanisation as a case-study. São Paulo: MASP, 2012, Manuscrito inédito usado com autorização dos autores. 
, GRILLO, J. Os conceitos de “helenização" e de "romanização” e a construção de uma Antiguidade Clássica. Manuscrito inédito usado com autorização dos autores. 2012

HINGLEY, R. O imperialismo romano: novas perspectivas a partir da Bretanha. São Paulo: Annablume, 2010.

HÜBSCHER, B. Arnaldo Momigliano: História da historiografia e do mundo antigo. Dissertação (Mestrado em História), Universidade de São Paulo, São Paulo, 2010.

JOUGUET, P. El imperialismo macedonico y la helenizacion del oriente. Barcelona: Cervantes, 1927.

MAIRS, R. "Hellenization" in BAGNALL, R., BRUDERSEN, K., CHAMPION, C., ERSKINE, A. HUEBNER, S. (orgs.) The Encyclopedia of Ancient History, Oxford University Press, 2011.

MÉCHIN, B. "História e poesia” in DROYSEN, J. Alexandre: o grande. Rio de Janeiro: Contraponto, pp. 15-31, 2010.

MOMIGLIANO, A. Os limites da helenização. Rio de Janeiro: Jorge Zahar Editor, 1991.

PEREMANS, W. "Pierre Jouguet (1869-1949). In Revue belge de philologie et d'historie. Tome 28, fasc 3-4, pp. 1576-1577. 1950.

REDFIELD, R., LINTON, R., HERSKOVITS, M. "Memorandum for the study of acculturation”, American Anthropologist, New Series, Vol. 38, No. 1 Jan. Mar, 149-152, 1936.

SILVA, G. História Antiga e usos do passado: um estudo das apropriações sob o regime de Vichy (1940-1944). São Paulo: Annablume-Fapesp, 2007.

SOUTHARD, R. Droysen and the Prussian School of History. Kentucky University Press, 1994.

WACHTEL, N. "A Aculturação” in LE GOFF, J. \& NORA, P. História: novos problemas. Rio de Janeiro, RJ: F. Alves, pp. 113-128, 1995. 